Book Review

ISSN: 2162-3104 Print/ ISSN: 2166-3750 Online

Volume 5, Issue 3 (2015), pp. 315-316

(C) Journal of International Students

http://jistudents.org/

\title{
Suggestions for International Students in the US
}

Sharma, P. (2013). Uncle Sam Calling: Hints for Being an International Student in USA. New Delhi, India: Pothi.com

Reviewed by Uttam Gaulee, University of Florida College of Education (USA)

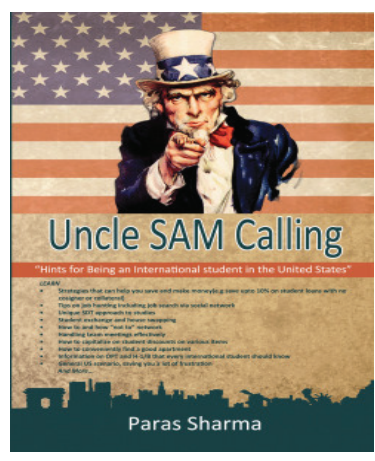

For international students transitioning into the US academic and social culture, as well as for those aspiring to make USA their higher education destination, Paras' book is a savvy guide and companion. The book provides a detailed guidance in an illustrative manner for aspiring international students on critical steps from the beginning of the admission process to documentation, travel, and transition. The way Paras has chronicled a lived experience of a successful student himself, is commendable.

The book is organized into 6 stages depicting journey of an international student in USA: a) Prior arrival, b) Arriving in the USA, c) Initial days at school, d) Getting settled, e) Final days at school, and f) After graduation.

The author covers many practical questions such as opening a bank account, applying for credit cards, obtaining the social security number, having a telephone-all of which he covers with insightful tips and tricks. Students can continue using this book even after they're settled because it also provides advice on a plethora of regular activities such as traveling, understanding highway systems, traffic laws, tolls, and taxes, and many other topics even local people often find confusing, are explained in an incredibly insightful way. The sequence is chronological, which makes it intuitively easy to find information depending on the stage of transition.

Topics related to academic success are also included. The author tells students what to expect when they first enter college/university, what they need to focus at first, and what not worry about immediately. As we move on, we find topics such as professional networking, college procedures, grading, involvement, team skills, and things necessary towards the final days of school, such as when to apply for OPT or CPT, or H1B or even preparing to move out of your apartment.

A successful international student in USA, the author has lived, studied, and worked in US for companies like Fidelity Investments, Chevron and TJX. During his journey, he came across challenges that most international students face such as managing money, adapting to a different culture, finding job in a new country, networking with potential employers etc. Having researched other successful students and including his own insights, he has consolidated and provided solutions to these challenges in his book Uncle Sam Calling - Hints for being an International Students in the United States. 
One useful aspect of the book I found is that there is a website [www.unclesamcalling.com] that could be used in conjunction with the book, without additional cost. It contains educational videos and interactive forum where international students from around the world can connect, learn from experiences of successful past students and help meet each other needs. For example, if one wants to know of a place in their home country where they can avail vaccination/immunization at a lower price as compared to in the USA, they can let the community on the forum know and be suitably helped with. The same applies to all other stages or topics of interest to students.

The best strength of the book is its wide range of practical coverage and the inclusion of some innovative techniques like elicitation technique to choose a school, SDT (Study Discuss Teach), and latest technical trends via Klout, linked in to choose a major, hunt for job and networking.

Here are some brief extracts from the book that give an idea of the topics and the way they are presented.

Internships tips: Internships are great opportunities, where you have more time to develop your skills and establish good networks with college seniors, professors, and professionals. Most scholarships are awarded for a full academic year, and are thus offered in the fall. Consequently, there are fewer opportunities for scholarships in the spring.

Getting involved: Most student organizations hold their elections in the fall. Some classes are offered only in the fall and these may function as prerequisites for spring classes.

Other suggestions: Most students opt to begin in the fall and, thus, graduate in the spring. Fall students have more opportunities to become TA's, RA's, or GA's."

The author has thoughtfully presented some interesting aspects of the US culture, which are important for the transitioning international students to understand how things are done around here once you are stateside.

While this book is not academic in nature and probably adds little to the body of knowledge. However, what this book does is that it makes it accessible in one convenient place for transitioning international students in a unique fashion so as to add a tremendous amount of knowledge and meaning to existing scholarship in the area.

The book initially comes across as small in size but the author has addressed this point in introduction. The author has deliberately kept the chapters brief and precise to make the optimal use of student's time, which is an important factor while studying. This should be used as a reference book.

The title of the book "Uncle Sam Calling" looks awkward in the beginning but as I read on, I could see where Paras comes from and this is entirely to the advantage of the bright eyed young students on the other side of the globe, aspiring to pursue their dream of academic excellence and happy life in USA. The book speaks directly to students' hopes, fears and doubts. Easy read as it is, the book is enhanced with pictures, drawings, references to online videos, and links to authentic sources of information for a comprehensive experience and understanding.

The book is available via all popular venues, including iTunes, and Amazon.com. 